\title{
Performance evaluation of corrosion-affected reinforced concrete bridge girders using Markov chains with fuzzy states
}

\author{
M B ANOOP* and K BALAJI RAO \\ CSIR-Structural Engineering Research Centre, CSIR Campus, Taramani, Chennai 600 113, India \\ e-mail: mbanoop@yahoo.com; balajiserc1@yahoo.com
}

MS received 11 September 2015; revised 10 January 2016; accepted 29 January 2016

\begin{abstract}
A methodology for performance evaluation of reinforced concrete bridge girders in corrosive environments is proposed. The methodology uses the concept of performability and considers both serviceability- and ultimate-limit states. The serviceability limit states are defined based on the degree of cracking (characterized by crack width) in the girder due to chloride induced corrosion of reinforcement, and the ultimate limit states are defined based on the flexural load carrying capacity of the girder (characterized in terms of rating factor using the load and resistance factor rating method). The condition of the bridge girder is specified by the assignment of a condition state from a set of predefined condition states. Generally, the classification of condition states is linguistic, while the condition states are considered to be mutually exclusive and collectively exhaustive. In the present study, the condition states of the bridge girder are also represented by fuzzy sets to consider the ambiguities arising due to the linguistic classification of condition states. A non-homogeneous Markov chain (MC) model is used for modeling the condition state evolution of the bridge girder with time. The usefulness of the proposed methodology is demonstrated through a case study of a severely distressed beam of the Rocky Point Viaduct. The results obtained using the proposed approach are compared with those obtained using conventional MC model. It is noted that the use of MC with fuzzy states leads to conservative decision making for the problem considered in the case study.
\end{abstract}

Keywords. Reinforced concrete; bridge girder; chloride-induced corrosion; performability; Markov chain; fuzzy sets.

\section{Introduction}

Development of rational methodologies for the evaluation of performance of civil infrastructure systems against different degradation mechanisms is an area of active research [1-5]. The importance of using soft computing techniques in infrastructure management is brought out by Flintsch and Chen [6]. Elhag and Wang [7] used artificial neural networks for modelling bridge risk score and risk categories for bridge maintenance priority ranking. A hierarchical evidential reasoning framework is proposed by Bolar et al [8] for condition assessment of bridges. The DempsterShafer theory and Yager rule of combination is used to aggregate different distress indicators at different hierarchical levels, considering both aleatory and epistemic uncertainties, to obtain an overall bridge condition index. Cheng and Hoang [9] proposed an artificial intelligence (AI) approach, based on evolutionary fuzzy least-squares support-vector machine inference model, for prioritizing bridges for maintenance. In this approach, ambiguity and subjective judgment in the bridge evaluation process is

*For correspondence handled using fuzzy logic. A hidden fuzzy inference system between input factors and risk score of bridges is developed using least-squares support-vector machine. However, in the most of the above studies, constructing the model requires database with sufficient number of evaluation cases, which can be difficult to obtain. Also, the models are only aimed at condition assessment of existing bridges and cannot be used for prediction of the future performance of the bridge, which is an integral part of performance-based design.

Chloride-induced corrosion of reinforcement is identified as one of the major degradation mechanisms for reinforced concrete (RC) members of infrastructural systems, especially for those located in the marine environment. In this paper, a methodology for performance evaluation of reinforced concrete structural members against chloride-induced corrosion of reinforcement, using the concept of performability, is proposed. Performability, defined as a measure combining reliability and performance measure, gives a more detailed and more accurate evaluation of the performance. In the proposed methodology, the condition of the bridge girder is described by assignment of a condition state. The stochastic evolution of condition of the RC 
bridge girder with time is modelled using a Markov chain (MC) model. Use of homogeneous MC models for modeling evolution of damage with time in bridge girders/ bridges has been proposed by various researchers [10-12]. However, the state transition probabilities from one fixed condition state to another need to be considered as a function of time. Thus, the use of a non-homogeneous MC model would be more rational.

Also, since the classification of states is based on linguistic description, the states can better be represented by fuzzy sets rather than crisp sets [13]. Use of fuzzy set theory provides a rational method to broaden the probability-based uncertainty handling framework to incorporate uncertainties arising due to linguistic description [14-16]. Hence, in this study, a non-homogeneous Markov chain (NHMC) model with fuzzy states is proposed for modeling condition evolution with time. The transition probability matrix (TPM) obtained for the crisp states is operated upon to obtain the TPM of the MC model with the fuzzified states. The performance of the bridge girder is quantified using performability measure. One of the requirements for performance-based engineering is to define quantitatively the different evaluation limit states [17]. In the present study, an attempt is made in this direction by providing quantitative definitions for different serviceability and ultimate limit states, which is required for performance-based condition assessment. The usefulness of the methodology is illustrated through the performance evaluation of a girder of the Rocky Point viaduct. The results obtained indicate that the proposed methodology will help in taking maintenance decisions. It is noted that the computation of performability will be useful for making engineering decisions for answering questions like 'How serviceable is the existing structure or how serviceable the (new) structure is going to be?'.

\section{Proposed methodology for performance evaluation}

The methodology proposed for performance evaluation of $\mathrm{RC}$ bridge girders using the MC model with fuzzy states involves the following steps.

Step 1: Determination of the condition state of the $\mathrm{RC}$ bridge girder at a given time using a deterministic method Step 2: Modelling the condition state evolution of the bridge girder with time using the conventional MC model Step 3: Determination of TPM of Markov chain with fuzzy states

Step 4: Computation of performability of the RC bridge girder

Step 5: Performance evaluation

The details related to each of these steps are given below.

\subsection{Determination of condition state of the girder - deterministic procedure}

The guidelines given by FHWA Bridge inspector's reference manual [18] are used in the present study for defining the condition state for the girder. It may be noted that these guidelines are applicable for the condition rating of the superstructure system; however, the same is used in this study for condition rating of the individual girder. This is justifiable, since 'the primary member rating represents the condition and functional capacity of the main members of the bridge span as a system' [19]. As specified in NYDoT [19], if the condition of a primary member is the controlling condition in a load path non-redundant system, the rating would be used for the primary member system. The condition states and their description are given in table 1.

In the present study, the condition of the bridge girder is specified by the assignment of a condition state. Chlorideinduced corrosion of reinforcement affects the safety against both the serviceability limit state (SLS) due to cracking of cover concrete of the $\mathrm{RC}$ bridge girder and the ultimate limit state (ULS) due to the reduction in load carrying capacity. These two aspects should be considered while carrying out condition state assessment of corrosionaffected RC bridge girders.

2.1a Modelling the reduction in area of reinforcement due to chloride-induced corrosion: Chloride-induced corrosion is one of the important degradation mechanisms for reinforced concrete structures located in marine environment. The chloride ions ingress through the cover concrete, and when the chloride concentration near the reinforcing steel exceeds a threshold (called the critical chloride concentration), corrosion initiates. There are several transport mechanisms such as diffusion, capillary sorption and permeation [20] for ingress of chlorides into concrete. The complex combination between these transport mechanisms should be considered for modeling the ingress of chlorides into concrete. However, for most of the cases, Fick's second law of diffusion can be used to model the chloride penetration into concrete. The time for corrosion initiation $\left(t_{i}\right)$ can be determined from Fick's second law of diffusion as [21]:

$$
t_{i}=\frac{d^{2}}{4 D}\left[\operatorname{erf}^{-1}\left(\frac{c_{s}-c_{c r}}{c_{s}}\right)\right]^{-2}
$$

where $d$ is the clear cover to reinforcement, $D$ is the diffusion coefficient for chlorides in concrete, erf is the error function, $c_{s}$ is the surface chloride concentration and $c_{c r}$ is the critical chloride concentration. Some of the limitations of the assumptions made in deriving this model are (i) concrete is neither homogeneous nor isotropic, (ii) chloride ions may be physically adsorbed onto surface of pores and chemically combined to aluminates forming chloroaluminate complexes, (iii) diffusion coefficient depends both on time and location/concentration. In spite of 
Table 1. Definition of condition states for RC bridge girder (based on Ryan et al [18]).

\begin{tabular}{|c|c|}
\hline $\begin{array}{l}\text { Condition } \\
\text { state }\end{array}$ & Description \\
\hline CS9 & Excellent condition \\
\hline CS8 & Very good condition: no problems noted \\
\hline CS7 & Good condition: some minor problems \\
\hline CS6 & Satisfactory condition: structural elements show some minor deterioration \\
\hline CS5 & Fair condition: all primary structural elements are sound but may have minor section loss, cracking or spalling \\
\hline CS4 & Poor condition: advanced section loss, deterioration, spalling or scour \\
\hline CS3 & $\begin{array}{c}\text { Serious condition: loss of section, deterioration or spalling has seriously affected primary structural components. Local } \\
\text { failures are possible. Shear cracks in concrete may be present }\end{array}$ \\
\hline $\mathrm{CS} 2$ & $\begin{array}{l}\text { Critical condition: advanced deterioration of primary structural elements. Shear cracks in concrete may be present. } \\
\text { Unless closely monitored, it may be necessary to close the bridge until corrective action is taken }\end{array}$ \\
\hline CS1 & $\begin{array}{c}\text { "Imminent" failure condition: major deterioration or section loss present in critical structural components. Bridge is } \\
\text { closed to traffic but corrective action may put back in light service }\end{array}$ \\
\hline CSO & Failed condition: out of service. Beyond corrective action \\
\hline
\end{tabular}

these limitations, the above equation is commonly used in the estimation of chloride profile in concrete and the time for corrosion initiation. Although more realistic models like the Mejlbro-Paulsen model [22], DuraCrete model [23], and fib Model Code model [24] are available in literature, the large amount of information required for applying these models prohibits their use except for very important projects. Hence, in the present study, the time for corrosion initiation is estimated using Eq. (1).

Researchers have proposed different models for determining the remaining area of reinforcing bar after corrosion initiation $[25,26]$. From a brief review of these models, it is found that the model proposed by Rodriguez et al [27] is generally used for determining the remaining diameter of reinforcing bar. This model is formulated based on Faraday's law, under the assumptions that the number of electrons freed by $\mathrm{Fe}$ ion during the corrosion reaction is two, the atomic mass of iron is $55.95 \mathrm{~g} / \mathrm{mol}$ and the mass density of iron is $7.88 \mathrm{~g} / \mathrm{cm}^{3}$ [26]. Although this model takes into consideration the localized pitting associated with chlorideinduced corrosion, the reduction in corrosion current with time is not taken into account. This model gives a conservative estimate for the remaining bar diameter in the case of pitting corrosion, as the corrosion pits are almost hemispherical in shape. Using this model, the remaining reinforcing bar diameter, $\phi(t)$ (in $\mathrm{mm}$ ), at any time $t$ (in years), is estimated as

$$
\phi(\mathrm{t})=\phi(0)-0.0116 \alpha I_{\text {corr }}\left(t-t_{i}\right) ; \quad t>t_{i}>0,
$$

where $\phi(0)$ is the original bar diameter, i.e., bar diameter before corrosion initiation, (in $\mathrm{mm}$ ), $I_{\text {corr }}$ is the corrosion current density (in $\mu \mathrm{A} / \mathrm{cm}^{2}$ ), 0.0116 is a factor which converts $\mu \mathrm{A} / \mathrm{cm}^{2}$ to $\mathrm{mm} / \mathrm{year}, t_{i}$ is the time for corrosion initiation (in years), and $\alpha$ is a factor for including the effect of localized pitting.

2.1b Safety against $S L S(S S)$ : In the present study, the SS is defined based on the degree of cracking (characterized by crack width) in the girder due to chloride induced corrosion of reinforcement. Models have been proposed by various researchers relating the level of corrosion to the formation of cracks. Based on the review of these models [28], the following models are chosen for the crack initiation and crack width propagation due to corrosion of reinforcement in concrete.

Loss in area of steel cross-section corresponding to crack initiation $\left(\Delta A_{s o}\right.$ in $\left.\mathrm{mm}^{2}\right)$ and evolution of maximum crack width $\left(w_{\max }(t)\right.$, in $\left.\mathrm{mm}\right)$ are given by (from Vidal et al [29]):

$$
\begin{gathered}
\Delta A_{s o}=A_{s}\left[1-\left[1-\frac{\alpha}{\phi(0)}\left(7.53+9.32 \frac{d}{\phi(0)}\right) \times 10^{-3}\right]^{2}\right] \\
w_{\max }(t)=0.101\left(\Delta A_{s}(t)-\Delta A_{s o}\right)
\end{gathered}
$$

where $A_{s}$ is the initial area of steel cross-section in $\mathrm{mm}^{2}$ and $\Delta A_{s}(t)$ is the loss in area of reinforcement at time $t$ (in $\mathrm{mm}^{2}$ ). Using Eqs. (3) and (4), the degree of cracking (characterized by the crack width) due to chloride-induced corrosion of reinforcement at any time can be determined based on the loss in area of reinforcement at that time. The SS for the bridge girder is determined based on the degree of cracking using the guidelines given in table 2 .

2.1c Safety against $U L S(S U)$ : In this study, it is assumed that the safety against ULS of the bridge girder at any time depends on the capacity of the girder to sustain the applied loads. While assessment of load carrying capacity is usually carried out using deterministic- or semi-probabilistic (partial safety factor)- approaches (which are sometimes considered to be conservative), reliabilitybased approaches explicitly taking into account the uncertainties in variables are emerging [3, 31-33]. The load and resistance factor rating (LRFR) method proposed by AASHTO [34] is reliability-based and provides a more 
Table 2. States of SS for the bridge girder.

\begin{tabular}{lc}
\hline SS state & Description \\
\hline 1 & Corrosion is yet to initiate \\
2 & Corrosion initiated, but no cracking \\
3 & Cracking initiated, but crack width less than the allowable value of $0.3 \mathrm{~mm}$ specified in code of practice (BIS 2000) \\
4 & Crack width greater than $0.3 \mathrm{~mm}$, but less than $1.0 \mathrm{~mm}$ (no spalling) \\
5 & Crack width $\geq 1.0 \mathrm{~mm}$, spalling of concrete [30] \\
\hline
\end{tabular}

Table 3. States of SU for the bridge girder.

\begin{tabular}{lcc}
\hline SU state & Definition & Description \\
\hline 1 & $\mathrm{RF}_{\mathrm{OL}} \geq 1.0$ & Bridge girder satisfies the design load rating at operating level \\
2 & $\mathrm{RF}_{\mathrm{OL}}<1.0$ and $\mathrm{RF}_{\mathrm{LL}} \geq 1.0$ & Bridge girder does not satisfy the design load rating, but satisfies the legal load rating \\
3 & $0.60 \leq \mathrm{RF}_{\mathrm{LL}}<1.0$ & Bridge girder does not satisfy the legal load rating; reduced loads can be permitted \\
4 & $0.30 \leq \mathrm{RF}_{\mathrm{LL}}<0.60$ & Bridge girder does not satisfy the legal load rating; highly reduced loads can be permitted \\
5 & $\mathrm{RF}_{\mathrm{LL}}<0.30$ & Bridge to be closed to traffic
\end{tabular}

$\mathrm{RF}_{\mathrm{OL}}$, rating factor for design load rating at operating level; $\mathrm{RF}_{\mathrm{LL}}$, rating factor for legal load rating.

Table 4. Rule base for determining the condition state.

\begin{tabular}{|c|c|c|c|c|c|}
\hline \multirow[b]{3}{*}{ Safety against SLS } & \multicolumn{5}{|c|}{ Safety against ULS } \\
\hline & \multicolumn{5}{|c|}{ SU state } \\
\hline & $\left(R F_{O L}^{1} \geq 1.0\right)$ & $\left(R F_{O L}<1.0\right.$ and $\left.R F_{E L} \geq 1.0\right)$ & $\begin{array}{c}3 \\
\left(0.6 \leq R F_{E L}<1.0\right)\end{array}$ & $\begin{array}{c}4 \\
\left(0.3 \leq R F_{E L}<0.6\right)\end{array}$ & $\begin{array}{c}5 \\
\left.R F_{E L}<0.3\right)\end{array}$ \\
\hline \multicolumn{6}{|l|}{ SS State } \\
\hline 1 (No corrosion) & CS9 & CS7 & CS5 & $\mathrm{CS} 3$ & CS1 \\
\hline $\begin{array}{l}2 \text { (Corrosion initiated; no } \\
\text { cracking) }\end{array}$ & CS8 & CS6 & CS5 & $\mathrm{CS} 2$ & $\mathrm{CS} 1$ \\
\hline $3($ Crackwidth $\leq 0.3)$ & CS7 & CS6 & CS4 & $\mathrm{CS} 2$ & $\mathrm{CS} 1$ \\
\hline $4($ Crackwidth $\leq 1.0)$ & CS5 & $\mathrm{CS} 4$ & CS4 & $\mathrm{CS} 2$ & $\mathrm{CSO}$ \\
\hline $5($ Crackwidth $>1.0)$ & $\mathrm{CS} 3$ & $\mathrm{CS} 3$ & $\mathrm{CS} 3$ & $\mathrm{CS} 2$ & CSO \\
\hline
\end{tabular}

realistic assessment of the safe load capacity of existing bridges [35]. Hence, this method is adopted in the present study for defining the SU. According to LRFR, the load rating is generally expressed as a rating factor (RF), given by AASHTO [34],

$$
\begin{array}{r}
R F=\frac{C-\gamma_{D C} D C-\gamma_{D W} D W \pm \gamma_{P} P}{\gamma_{L} L L(1+I M)} \\
C=\phi_{c} \phi_{s} \phi R_{n} \text { with } \phi_{c} \phi_{s} \geq 0.85
\end{array}
$$

where $C$ is the capacity, $R_{\mathrm{n}}$ is the nominal member resistance, DC is the dead load effect due to structural components and attachments, DW is the dead load effect due to wearing surface and utilities, $\mathrm{P}$ is the permanent loads other than dead loads, LL is the live load effect, IM is the dynamic load allowance and is equal to $10 \%$ for fatigue and fracture limit states and $33 \%$ for other limit states, $\gamma_{D C}$ is the LRFD load factor for structural components and attachments and is equal to 1.25 for RC bridges, $\gamma_{\mathrm{DW}}$ is the LRFD load factor for wearing surface and utilities and is equal to 1.50 for $\mathrm{RC}$ bridges ( $\gamma_{\mathrm{DW}}$ can be taken as 1.25 if the thickness is field measured), $\gamma_{P}$ is the LRFD load factor for permanent loads other than dead loads and is equal to 1.0 and $\gamma_{\mathrm{L}}$ is the evaluation live load factor and is equal to 1.35 for operating level rating and 1.65 for legal load rating for RC bridges. $\varphi_{\mathrm{c}}$ is the condition factor for taking into 
account the increased uncertainty in the resistance of deteriorated members, and varies from 0.85 for members in poor condition to 1.0 for members in good or satisfactory condition, $\varphi_{\mathrm{s}}$ is the system factor for taking into consideration the level of redundancy of the entire super structure, and varies from 1.0 for redundant multi-girder bridges to 0.85 for non-redundant systems such as two-girder, welded girder- and truss- bridges. $\varphi$ is the LRFD resistance factor and is given as 1.0 (as per [34]).

The methodology for LRFR comprises three distinct procedures: (1) design load rating, (2) legal load rating, and (3) permit load rating. The permit load rating is required for the issuance of overweight permits based on request, and applies only to bridges that satisfy the legal load rating. Therefore, this level of rating is not considered in the present study for determining the SU of the girder.

For a bridge girder subjected to chloride-induced corrosion of reinforcement, the nominal resistance will reduce with time after corrosion initiation, due to the reduction in area of reinforcement (the effect of other factors like creep and shrinkage of concrete, loss of bond between steel and concrete is not considered in the present study). Once the reduced diameter of the reinforcing bars is determined [using Eq. (2)], the rating factors for the girder can be computed. The SU for the bridge girder at any time is determined based on the value of rating factor at that time using the conditions given in table 3 .

2.1d Determination of condition states: After determining the safety against the serviceability limit state (SS) and the safety against ultimate limit state (SU) at any time, the condition state (CS) at that time of the girder is determined. For this purpose, a rule base is formulated in this paper relating the SU and SS to the condition state of the girder (see table 4). More details regarding the formulation of rule base are given in Anoop [28]. Table 4 can be used to classify/assess the (corrosion) condition state of the bridge girder. The feature of this table, as can be noted, is combining the information presented in tables 1-3.

To account for variations in workmanship and exposure conditions, $d, D, c_{s}, c_{c r}, I_{\text {corr }}$ and $\alpha$ are treated as random variables, and the condition state evolution of the bridge girder with time is modelled using a MC model. To estimate the elements of the TPM to describe the stochastic evolution, the procedure presented in the next section is used.

\subsection{Stochastic modelling of the condition state evolution}

Markov chains are found to be a useful tool for stochastic modelling of condition state evolution of a system with time [11, 12, 36-39]. Using data on bridge superstructure condition rating from United States and Hungary, Chase and Gáspár [12] have shown that predictions on condition state using $\mathrm{MC}$ are in good agreement with the observed condition states. Therefore, in the present study, MC modelling is used for the condition evolution of the bridge girder with time. The index space of this stochastic process is the time, which can be considered as discrete, $\left\{\mathrm{T}_{1}, \mathrm{~T}_{2}, \ldots\right\}$. The state space of the stochastic process represents the condition state of the girder, which is also discrete, $\mathrm{S}=\{\mathrm{CS} 9, \mathrm{CS} 8$, $\ldots, \mathrm{CS} 0\}$. Hereafter, the condition states are represented as $\mathrm{S}=\left\{C S_{9}, C S_{8}, \ldots, C S_{0}\right\}$. The probabilistic evolution of the bridge girder is given by the TPM. Since, due to chlorideinduced corrosion, the cross-sectional area of reinforcement reduces with time, there is transition only from higher condition states to the lower condition states. Therefore, the TPM will be an upper triangular matrix.

Balaji Rao et al [10] used a homogeneous MC for corrosion damage evolution with time. Many of the bridge management systems, such as Pontis, also use homogeneous MC for modeling deterioration of bridge components and systems with time [40]. However, since the state transition probabilities from one fixed condition state to another are not constant with time, the use of a NHMC model would be more rational $[36,41]$. Hence, in this study, a NHMC model is proposed for modelling the condition evolution with time. Monte Carlo simulation (MCS) approach is used for determining the elements of the TPM. While the MCS approach can be used directly for determining the condition state probabilities, it is easy to propagate the dependencies using a MC model which helps in decision making. Also, the results of condition state assessment based on inspection can be incorporated in a MC model [10]. The step-by-step procedure for determining the elements of the TPM (P) for the condition state evolution between two successive time instants, $T_{k}$ and $T_{k+1}$, is given below.

1. Select values of mean and $\mathrm{COV}$ for $D, c_{s}, c_{c r}$, cover thickness $(d), I_{\text {corr }}$ and $\alpha$. Assume cover thickness $(d)$, $I_{\text {corr }}$ and $\alpha$ follows lognormal distribution.

2. Determine mean and standard deviation of time to corrosion initiation (Eq. 1) using first order approximation. Assume $t_{i}$ follows a lognormal distribution.

3. Carry out MCS at two successive time instants, $T_{k}$ and $T_{k+1}$ considering $t_{i}, I_{\text {corr }}$ and $\alpha$ as random variables.

For each time instant and for each simulation

(a) Determine the remaining diameter of the reinforcing bar (Eq. 2) and the loss in area of reinforcement

(b) Compute the width of the crack formed due to corrosion (using Eq. 4) and identify the safety against SLS (SS) using table 2

(c) Carry out LRFR and identify the safety against ULS (SU) using table 3

(d) Determine the condition state (CS) for the girder using the rule base given in table 4

4. Compute the elements of the TPM as 


$$
\begin{aligned}
\mathrm{P}(i, j)=p_{i j} & =\frac{\operatorname{Pr}\left(C S=C S_{m}\left|T=T_{k+1} \cap C S=C S_{l}\right| T=T_{k}\right)}{\operatorname{Pr}\left(C S=C S_{l} \mid T=T_{k}\right)} ; 1 \leq i \leq 10 ; i \leq j \leq 10 ; l=10-i ; m=10-j \\
& =\frac{\text { number of simulation cycles for which } C S=C S_{m} \text { at time } T_{k+1} \text { and } C S=C S_{l} \text { at time } T=T_{k}}{\text { number of simulation cycles for which } C S=C S_{l} \text { at time } T=T_{k}} .
\end{aligned}
$$

2.2a Markov chain model with fuzzy states: From table 1, it is noted that the condition states are defined using linguistic terms (such as excellent condition, poor condition, and critical condition). The uncertainties arising out of the use of linguistic terms can be modelled more rationally in the framework of fuzzy set theory. Hence, it is more appropriate to represent the condition states by fuzzy sets. Also, the number of states is large (10 states), and there is a need to aggregate the states of the system to make decisions regarding the maintenance. This is because: (i) the condition states do not adequately reflect the improvement needs [42] and (ii) the number of decision alternatives is generally limited (for instance, 'no maintenance actions', 'minor maintenance actions', and 'significant repair interventions' [40]). Fuzzifying the state space provides a rational framework for aggregating the states for decision making [43]. The TPM of MC model with fuzzy states $\left(\mathrm{P}_{\mathrm{F}}\right)$ can be determined from the TPM of MC model with discrete states, obtained at Step 4 above, using the following formulations given in Bhattacharyya [43] and Symeonaki and Stamou [44].

Let $S=\{1,2, \ldots, k\}$ be the discrete state space, and $F=$ $\left\{F_{1}, F_{2}, \ldots, F_{N}\right\}$ be the fuzzy state space, i.e., the set of fuzzy states. $F_{r}$ is a fuzzy set on $S$ and $\mu_{F_{r}}():. S \rightarrow[0,1]$ denotes the membership function of $F_{r}$ for $r=1,2, \ldots, N$, which satisfies the orthogonality conditions $\sum_{r=1}^{N} \mu_{F_{r}}(i)=$ 1 for all $i \in S$. Then the elements of TPM of the MC model with fuzzy states are given by

$p_{F_{r} F_{s}}=\left(m_{F_{r}}\right)^{-1} \sum_{i=1}^{k} \sum_{j=1}^{k} p_{i j} \mu_{F_{r}}(i) \mu_{F_{s}}(j) ; \quad m_{F_{r}}=\sum_{i=1}^{k} \mu_{F_{r}}(i)$.

In the present study, three fuzzy states are considered, $\mathrm{F}$ $=\{$ GOOD, AVERAGE, POOR $\}$. The grades of membership of the original non-fuzzy states $\left\{C S_{9}, C S_{8}, \ldots, C S_{0}\right\}$ in the fuzzy states are given in table 5. While the TPM of the MC model with discrete condition states will be an upper triangular matrix (as explained earlier), the same cannot be expected for the TPM of the MC model with fuzzy condition states, due to the interaction between the fuzzy sets.

After modeling the condition evolution of the girder with MC model, the next step is to determine the performability of the girder, and the same is explained in the next section.

\subsection{Performability}

Performability models, also called stochastic reward models (Sanders and Meyer [45], consist of a stochastic process and a reward structure. The stochastic process describes the evolution of the system. MC models are most commonly used in performability analysis for describing the stochastic evolution of the system [46]. In such a case, the process is often referred to as a structure-state process, since it describes the state of the system structure. The set of rewards associated with the states of a structure-state process are referred to as the reward structure.

The reward structure relates possible behaviours of the process to a specified performance variable. Typically, this is done by associating a 'reward rate' with each state, the interpretation being that this rate is the rate at which reward accumulates while the process is in the state. The reward structure is typically a set of one or more functions defined over the states or on transitions between the states in the process [45]. Thus, two kinds of reward can be distinguished, namely, (i) Rate reward: reward obtained when the system is in a certain discrete state and (ii) Impulse reward: reward obtained with some 'event' of the process, i.e., for instance, transition from one state to another.

Once the reward structure is specified, the performance variable can be defined in terms of the reward structure. The performance variables can be [45]:

Table 5. Membership functions of fuzzy condition states.

\begin{tabular}{lcccccccccc}
\hline & CS9 & CS8 & CS7 & CS6 & CS5 & CS4 & CS3 & CS2 & CS1 & CS0 \\
\hline Good & 1 & 1 & 1 & 0.6 & 0 & 0 & 0 & 0 & 0 \\
Average & 0 & 0 & 0 & 0.4 & 1 & 1 & 0.5 & 0 & 0 \\
Poor & 0 & 0 & 0 & 0 & 0 & 0 & 0.5 & 1 & 1 & 1 \\
\hline
\end{tabular}


- Instant-of-time variable: the variable typically represents the states of the modelled system at some time ' $t$ ' (instantaneous reward)

- Interval-of-time variable: the variable typically represents the accumulated benefit derived from operating the system for some interval of time (accumulated reward), and,

- Time-averaged interval-of-time variable: the variable represents the (time-averaged) rate at which reward is accumulated during an interval of time, obtained by dividing the reward accumulated during some time interval by the length of the interval (time-averaged accumulated reward).

2.3a Computation of performability: Let the vector $r$ represent the reward structure (i.e., $r_{i}$ is the reward rate assigned to the bridge girder if the bridge girder is in condition state $\left.C S_{i}\right)$. Let $C S\left(T_{k}\right)$ be the vector representing the condition state of the girder at time $T_{k}$. Then the random variable $Z\left(T_{k}\right)=r_{C S\left(T_{k}\right)}$ refers to the instantaneous reward rate of the girder at time $T_{k}$ [46]. The expected instantaneous reward rate and the variance of the instantaneous reward rate are given by [46, 47]:

$$
\begin{aligned}
& E\left[Z\left(T_{k}\right)\right]=\sum_{i \in S} r_{i} P_{i}^{U}\left(T_{K}\right) \\
& \operatorname{Var}\left[Z\left(T_{k}\right)\right]=\sum_{i \in S} r_{i}^{2} P_{i}^{U}\left(T_{K}\right)-\left(\sum_{i \in S} r_{i} P_{i}^{U}\left(T_{K}\right)\right)^{2}
\end{aligned}
$$

where $P^{U}\left(T_{k}\right)$ unconditional probability vector of the condition states at time $T_{k}$.

The probability that the instantaneous reward rate does not exceed to a certain performance level at time $T_{k}$ is given by [46]:

$$
p_{z}\left(T_{k}\right)=\operatorname{Pr} o b\left[Z\left(T_{k}\right) \leq z\right]=\sum_{i \in S, r_{i} \leq z} P_{i}^{U}\left(T_{K}\right) .
$$

The accumulated reward, $W\left(T_{k}\right)$, the expected accumulated reward, $E\left[W\left(T_{k}\right)\right]$, and the expected time-averaged accumulated reward, $E\left[Y\left(T_{k}\right)\right]$, over the period $\left(T_{1}, T_{k}\right)$ is given by [48]:

$$
\begin{aligned}
W\left(T_{k}\right) & =\sum_{j=2}^{k} Z\left(T_{j}\right) ; E\left[W\left(T_{k}\right)\right] \\
& =\sum_{j=2}^{k} \sum_{i \in S} r_{i} P_{i}^{U}\left(T_{j}\right) ; E\left[Y\left(T_{k}\right)\right] \\
& =\frac{1}{\left(T_{k}-T_{1}\right)} \sum_{j=2}^{k} \sum_{i \in S} r_{i} P_{i}^{U}\left(T_{j}\right) .
\end{aligned}
$$

2.3b Specification of reward rates - proposed structure: The set of rewards associated with the different states of the system is called the reward structure. It relates possible behaviours of the process to a specified performance variable. For instance, consider a binary reward structure $r$ defined such that a value of $r=1$ is assigned to the 'up' states of the system and $r=0$ is assigned to the 'down' states of the system. In this case, $E\left[Z\left(T_{k}\right)\right]$ gives the reliability of the system at time $T_{k}$, while $E\left[W\left(T_{k}\right)\right]$ gives the expected 'uptime' for the system over the period $\left(T_{1}, T_{k}\right)$. If the reward structure $r$ is considered such that $r_{i}$ represents the capacity of the system in state ' $i$ ', then $E\left[Z\left(T_{k}\right)\right]$ gives the expected instantaneous capacity of the system at time $T_{k}$ and $p_{z}\left(T_{k}\right)$ gives the probability that the capacity of the system does not exceed ' $z$ ' at time $T_{k}$. If $r_{i}$ represents the loss occurring due to the system being in state ' $i$ ', then $E\left[Z\left(T_{k}\right)\right]$ gives the expected instantaneous loss at time $T_{k}$ and $E\left[W\left(T_{k}\right)\right]$ gives the expected cumulative loss over the period $\left(T_{1}, T_{k}\right)$. Some of the commonly used reward structures are presented in Bolch et al [46].

The reward rates can be stationary (reward rate do not change with time) or dynamic (reward rate changes with time). Since the service life of bridge girders is long (typically 75 years), it is more rational to consider a dynamic reward rate. It makes more sense to assign a higher reward rate for the bridge girders if it is at a given condition state at the final stages of its service life than when it is the same condition state at the initial stages. To study the effect of different types of reward rates, two reward structures are proposed in this study for the computation of performability. These reward structures are explained below.

Reward structure I: The reward rates are assigned based on the urgency of maintenance when the girder is in different condition states (table 6). The maintenance urgency guidelines given in Ryan et al [18] are used for this purpose. Since the reward rate changes from 0 for no immediacy of maintenance action to 1.0 for immediate maintenance action, it is more appropriate to term it as a penalty rate rather than reward rate. The threshold values of $E\left[Z\left(T_{k}\right)\right]$ for maintenance management decisions are proposed as 0.40 for inspection and 0.60 for repair.

Reward structure II: The reward rates are assigned based on the non-dimensionalized weight of the legal load rating vehicle that can be permitted when the girder is in different condition states (table 6). The rewards are determined by first identifying the minimum safety states corresponding to the different condition states, and then determining the

Table 6. Reward structures considered.

\begin{tabular}{lcc}
\hline $\begin{array}{l}\text { Condition } \\
\text { state }\end{array}$ & $\begin{array}{c}\text { Reward structure I: penalty } \\
\text { rate (urgency of maintenance) }\end{array}$ & $\begin{array}{c}\text { Reward structure II: } \\
\text { (quality of service) }\end{array}$ \\
\hline Good & 0 & 1.0 \\
(No immediacy of & \\
maintenance action) & 0.5 \\
Poor & $\begin{array}{c}\text { (Maintenance within current } \\
\text { season) } \\
\end{array}$ & $\begin{array}{c}1.0 \\
\text { (Immediate maintenance) }\end{array}$ \\
\hline
\end{tabular}


average rating factor for these safety states. The threshold values of $E\left[Z\left(T_{k}\right)\right]$ for maintenance management decisions are proposed as 0.70 for inspection and 0.50 for repair.

\subsection{Performance evaluation}

After computing the performability, the performance evaluation of the bridge girder can be carried out using the performance variables defined in the previous section, namely, instantaneous reward rate, accumulated reward and timeaveraged accumulated reward. The accumulated reward and the time-averaged accumulated reward are relatively insensitive to the state of the system at a particular instance as compared to the instantaneous reward, especially at large times [49]. Hence, the instantaneous reward will be more useful for making decisions on inspection, repair or replacement which should be based upon the state of the system at a given time. The accumulated reward and timeaveraged accumulated reward will be useful for comparing the performances of different alternatives (for instance, for comparing the performances of different design alternatives over a period of time for selecting the best alternative).

Performance evaluation considering Reward structure I will be useful for comparing the maintenance urgency for different bridge girders for planning of maintenance and allocation of resources. In this case, $E\left[Z\left(T_{k}\right)\right]$ gives the expected value of immediacy of maintenance at time $T_{k}$, while $p_{z}\left(T_{k}\right)$ gives the probability that the immediacy of maintenance of the girder does not exceed a specified value of immediacy of maintenance at time $T_{k}$. Reward structure II will be useful as a measure of quality of service offered by the bridge girder. In this case, $E\left[Z\left(T_{k}\right)\right]$ gives the expected instantaneous quality of service at time $T_{k}, E\left[W\left(T_{k}\right)\right]$ gives the expected accumulated quality of service over the period $\left(T_{1}, T_{k}\right)$, and $p_{z}\left(T_{k}\right)$ gives the probability that the quality of service of the girder does not exceed a specified value ' $z$ ' at time $T_{k}$.

The use of the proposed methodology for performance evaluation is illustrated through an application in the next section.

\section{Case study}

In order to demonstrate the usefulness of the proposed methodology for performance evaluation, the Rocky Point Viaduct, located near Port Orford, Oregon, at a coastal site 25 m east of Pacific Ocean, is considered (see figure 1). The Viaduct had five spans with a total length of $114 \mathrm{~m}$ and a deck width of $10.6 \mathrm{~m}$. The inspection and maintenance records of the Viaduct, relevant to the present study, are given below [50, 51].

- 1955 - Viaduct constructed;

- July 1967 - first report of maintenance problems with the Viaduct;

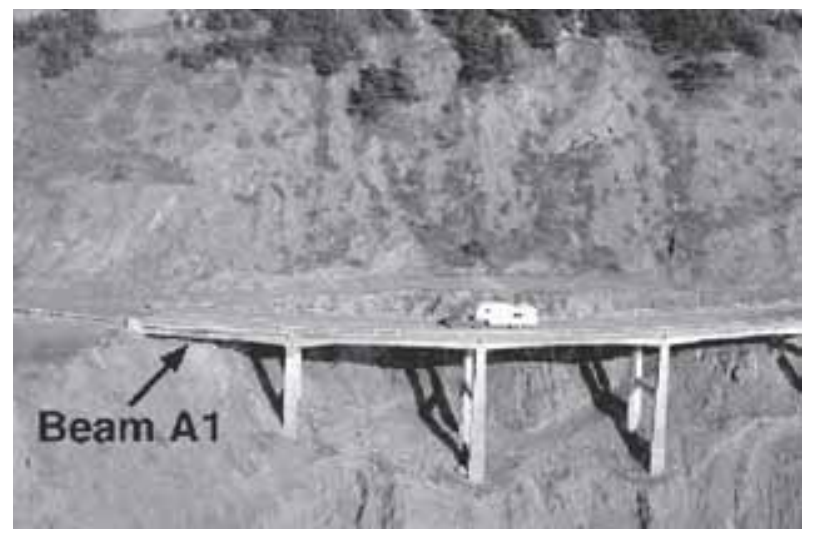

Figure 1. The Rocky Point Viaduct (from Covino et al [50]).

- May 1968 - cracking of concrete beams;

- January 1969 - spalling of concrete; badly rusted rebars;

- September 1969 - first repairs made;

- May 1976 - substantial section loss from corroded rebars;

- February 1991 - decision to replace the structure;

The extreme west edge beam of the Viaduct (beam A1 in figure 1), which was nearer to the ocean and thus was exposed to the full impact of the weather from the ocean, is considered in the present study. The cross-sectional details of the beam, based on information obtained from Covino et al [50] and Cramer et al [51], are given in figure 2. Other salient data required for the analysis, based on results of field investigations/design specifications $[50,51]$ are as follows:

\begin{tabular}{|c|c|}
\hline Span of the beam & $=20 \mathrm{~m}$ \\
\hline $\begin{array}{l}\text { Surface chloride concentration, } \mathrm{c}_{\mathrm{s}} \text { (from } \\
\text { chloride profiles) }\end{array}$ & $=\underset{\text { concrete }}{9.58 \mathrm{kgCl} / \mathrm{m}^{3} \text { of }}$ \\
\hline Critical chloride concentration, $\mathrm{c}_{\mathrm{cr}}$ & $=\underset{\text { concrete }}{0.5 \mathrm{kgCl} / \mathrm{m}^{3} \text { of }}$ \\
\hline $\begin{array}{l}\text { Diffusion coefficient for chlorides in } \\
\text { concrete, D (from chloride profiles) }\end{array}$ & $=\underbrace{1.24 \times 10^{8} \mathrm{~cm}^{2} /}_{\mathrm{s}}$ \\
\hline Water-cement ratio & $=0.53$ \\
\hline th of steel rebars & $=556 \mathrm{~N} / \mathrm{mm}^{2}$ \\
\hline Area of & $=1444 \mathrm{~mm}^{2}$ \\
\hline Compression strength of concrete cylinders & $=42.7 \mathrm{~N} / \mathrm{mm}^{2}$ \\
\hline \multicolumn{2}{|l|}{ Side cover to main reinforcement (d): } \\
\hline Minimum cover thickness & $=52.0 \mathrm{~mm}$ \\
\hline Averag & $=67.5 \mathrm{~mm}$ \\
\hline Maximum cover thickness & $=82.0 \mathrm{~mm}$ \\
\hline
\end{tabular}

The approximations/assumptions made with respect to the cross-sectional details of the beam considered in the study are given in Anoop et al [52]. The values of mean and coefficient of variation (COV) of the random variables considered are given in table 7 . It has been noted that both 


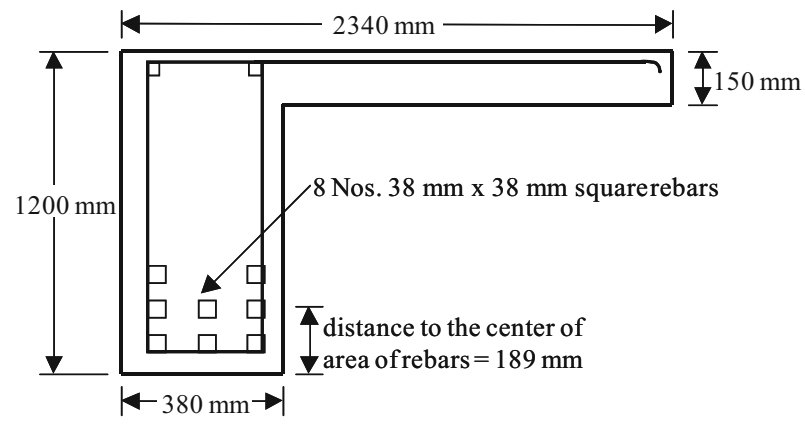

Figure 2. Cross-sectional details of the edge beam of the Rocky Point viaduct.

Table 7. Statistical properties of the random variables considered.

\begin{tabular}{lcc}
\hline Variable & Mean & $\mathrm{COV}^{\mathrm{a}}$ \\
\hline$d(\mathrm{~mm})$ & 67.5 & 0.05 \\
$D\left(\mathrm{~cm}^{2} / \mathrm{s}\right)$ & $1.24 \times 10^{8}$ & 0.20 \\
$c_{s}\left(\mathrm{kgCl} / \mathrm{m}^{3}\right.$ of concrete $)$ & 9.58 & 0.20 \\
$c_{c r}\left(\mathrm{kgCl} / \mathrm{m}^{3}\right.$ of concrete $)$ & 0.50 & 0.20 \\
$i_{\text {corr }}$ & 6.5 & 0.20 \\
$\alpha$ & 5.25 & 0.20 \\
\hline
\end{tabular}

${ }^{\mathrm{a}}$ The COV values are assumed.

Table 8. Values of load effects and load factors to be used in load rating for the bridge girder considered.

\begin{tabular}{lcc}
\hline Parameter & Moment (KN-m) & Load factor \\
\hline DC & 896.3 & 1.25 \\
DW & 217.6 & 1.25 \\
LL & 1226.2 & \\
Design load & 699.3 & 1.35 \\
Legal load Type 3 & 751.3 & 1.65 \\
Legal load Type 3S2 & 696.2 & 1.65 \\
Legal load Type 3-3 & & 1.65 \\
\hline
\end{tabular}

$I_{\text {corr }}$ and $\alpha$ show large variations [39], and hence, in this study, a value of COV of 0.20 is assumed for these variables. All the random variables are assumed to be statistically uncorrelated with each other. The mean and standard deviation of time-to-corrosion initiation is determined using first order approximation, and it is assumed that $t_{i}, d, I_{\text {corr }}$ and $\alpha$ follows lognormal distribution.

For determination of SU, the ultimate limit state of flexure is only considered in this study. The results of the dead load analysis and live load analysis for the bridge girder considered are given in table 8. Monte Carlo simulation method with 10 million cycles is used for determining the elements of TPM at different time-steps.

\subsection{Comparison with state probabilities obtained using conventional MC model}

The unconditional state probabilities and performability of the bridge girder, at the end of each year, are also computed using conventional MC model, for the purpose of comparison. The ten condition stares are aggregated into three states, namely, Aggregated state I (aggregating the states $\mathrm{CS}_{9}, \mathrm{CS}_{8}, \mathrm{CS}_{7}$ and $\mathrm{CS}_{6}$ ), Aggregated state II (aggregating the states $\mathrm{CS}_{5}, \mathrm{CS}_{4}$ and $C S_{3}$ ), and Aggregated state III (aggregating the states $C S_{2}, C S_{1}$ and $C S_{0}$ ). The TPMs (of size $3 \times 3$ ) at different times are obtained from MCS using a procedure similar to that presented in section 2.2. These TPMs are used for modeling the condition state evolution of the bridge girder with time. The aggregation is carried out by adding the unconditional probabilities of the corresponding condition states. The Aggregated states I, II and $I I I$ can be considered as the crisp counterparts of the fuzzy states GOOD, AVERAGE and POOR, respectively.

\section{Results and discussion}

The mean and COV of time for reaching the different serviceability- and safety- limit states are given in table 9 . From table 9, it is noted that the serviceability limit states govern the performance of the structure. The evolution of fuzzy condition states (namely, GOOD, AVERAGE and $P O O R$ ) with time along with the state probabilities obtained using conventional MC model are shown in figure 3. From the second year onwards, the probability of the bridge girder being in the AVERAGE condition state (namely, $A V E R A G E$ ) is non-zero. It is also noted that the probability of bridge girder being in POOR condition state is higher than probabilities for being in $G O O D$ and AVERAGE condition states from about 13th year onwards. This suggest that there is a need to take up urgent maintenance measures after 13 years. This is in agreement with the field observations, wherein the need for maintenance was first reported within 12 years of service.

After modelling the condition state evolution of the bridge girder with time using MC, the performance evaluation is carried out using the different performance variables. The results of performance evaluation with respect to

Table 9. Time to reach different serviceability- and ultimatelimit states for the bridge girder considered.

\begin{tabular}{lccccccc}
\hline \multicolumn{2}{l}{ States of SS } & & & \multicolumn{3}{l}{ States of SU } \\
\cline { 1 - 3 } \cline { 6 - 8 } SS state & Mean (years) & COV & & SU state & Mean (years) & COV \\
\hline 2 & 15.96 & 0.23 & & 2 & 61.34 & 0.22 \\
3 & 17.78 & 0.21 & & 3 & 71.47 & 0.23 \\
4 & 17.90 & 0.21 & & 4 & 86.22 & 0.24 \\
5 & 18.19 & 0.21 & & 5 & 101.39 & 0.24 \\
\hline
\end{tabular}




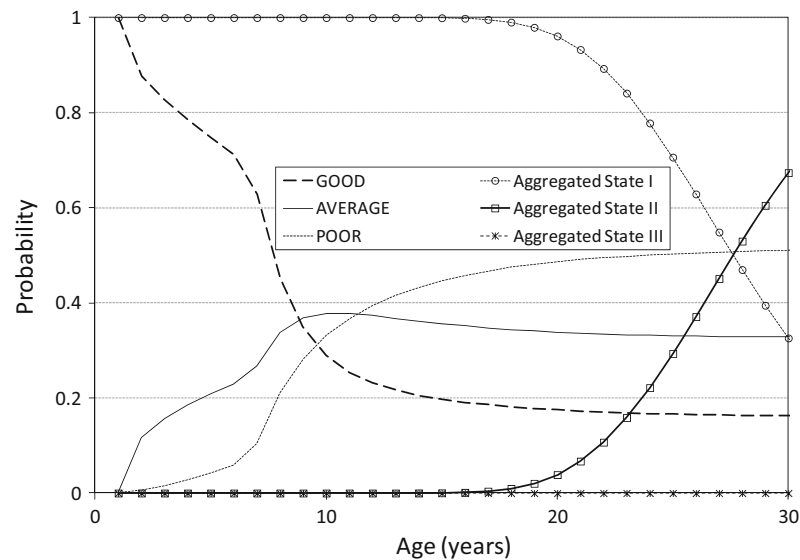

Figure 3. Evolution of condition states of the bridge girder with time using NHMC with fuzzy condition states.

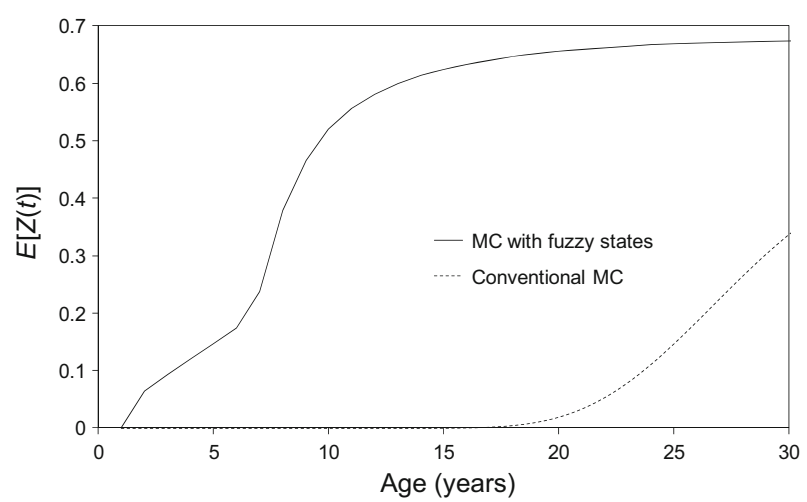

Figure 4. Variation of expected instantaneous penalty rate (urgency of maintenance) with time.

the two different reward structures considered are given below.

\subsection{Reward structure i (immediacy of maintenance)}

The expected values of immediacy of maintenance $\left(E\left[Z\left(T_{k}\right)\right]\right)$ for the bridge girder at different times are computed using Eq. (8) for both the methods considered. The variation of $E\left[Z\left(T_{k}\right)\right]$ with time is shown in figure 4 . Since the reward rates are assigned as penalty in this case, the value of $E\left[Z\left(T_{k}\right)\right]$ increases with time reflecting that the immediacy of maintenance increases as the bridge girder ages. From figure 4, it is noted that when MC model with fuzzy states is used, the expected immediacy of maintenance is non-zero from the second year onwards, while for the conventional MC model, the expected immediacy of maintenance is non-zero only from the tenth year onwards. This is due to the overlap between the fuzzy condition states which brings in more conservatism and rationality

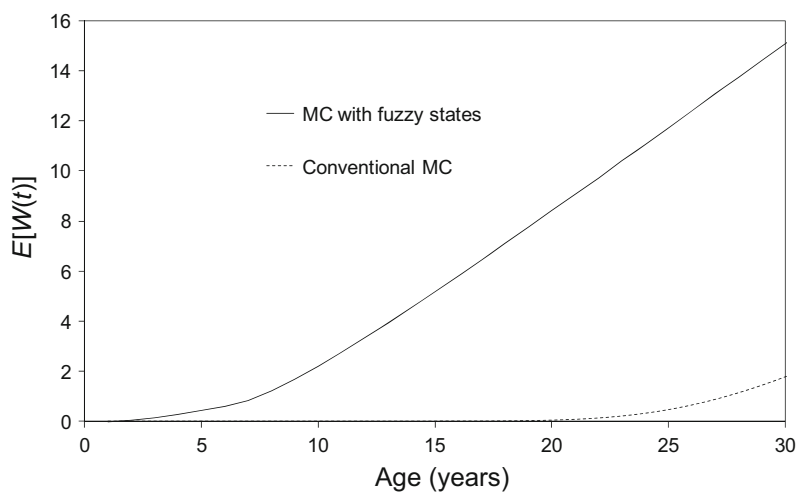

Figure 5. Variation of expected accumulated penalty (urgency of maintenance) with time.

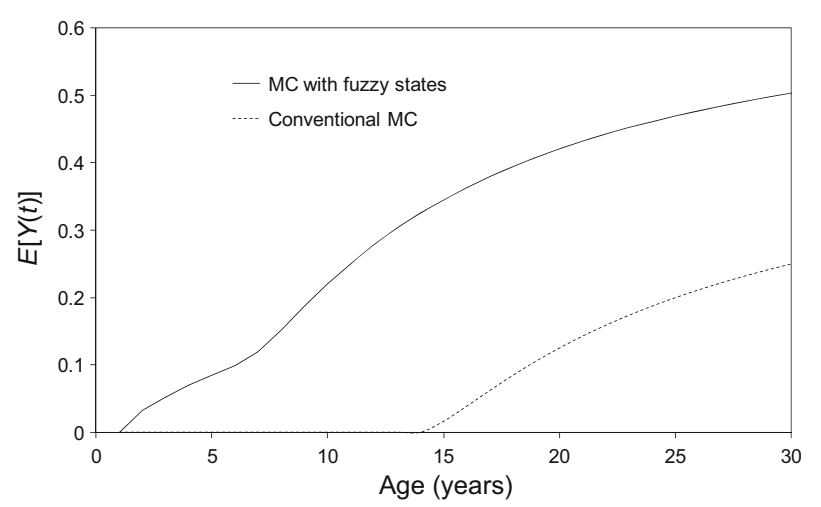

Figure 6. Variation of expected time-averaged accumulated penalty (urgency of maintenance) with time.

into the performance evaluation. The values of $E\left[W\left(T_{k}\right)\right]$ and $E\left[Y\left(T_{k}\right)\right]$ for different times are also computed using Eq. (10) and are shown in figures 5 and 6, respectively. It is noted that the value of $E\left[Y\left(T_{k}\right)\right]$ is less compared to the value of $E\left[Z\left(T_{k}\right)\right]$ at any given time. This is expected since $E\left[Y\left(T_{k}\right)\right]$ is the time-averaged measure as can be noted from Eq. (10). The times to reach the threshold values of $E\left[Z\left(T_{k}\right)\right]$ for maintenance management decisions are determined and are given in table 10. From table 10, it is noted that the time for inspection and repair predicted using the proposed approach are in agreement with the time for observed damage and repair of the actual bridge girder.

\subsection{Reward structure II (quality of service)}

The expected values of quality of service $\left(E\left[Z\left(T_{k}\right)\right]\right)$ at different times are computed using Eq. (8), and are shown in figure (7). It is noted from figure 7 that, as expected, the expected quality of service decreases with time. From figure 7 , it is noted that the expected quality of service starts reducing from the second year onwards. It is also noted 
Table 10. Time for maintenance management decisions for the bridge girder considered.

\begin{tabular}{|c|c|c|c|c|}
\hline \multirow[b]{2}{*}{ Maintenance action } & \multirow[b]{2}{*}{ Reward structure } & \multirow[b]{2}{*}{ Method } & \multicolumn{2}{|c|}{ Time (years) } \\
\hline & & & Predicted & Observed $^{\mathrm{a}}$ \\
\hline \multirow[t]{4}{*}{ Inspection } & I & Proposed approach (MC model with fuzzy condition states) & 8 & $\approx 12$ \\
\hline & (urgency of maintenance) & Conventional MC model & 16.5 & \\
\hline & II & Proposed approach (MC model with fuzzy condition states) & 7.5 & \\
\hline & (quality of service) & Conventional MC model & 24 & \\
\hline \multirow[t]{4}{*}{ Repair } & $\mathrm{I}$ & Proposed approach (MC model with fuzzy condition states) & 13 & $\approx 14$ \\
\hline & (urgency of maintenance) & Conventional MC model & 68 & \\
\hline & II & Proposed approach (MC model with fuzzy condition states) & 12 & \\
\hline & (quality of service) & Conventional MC model & $>75$ & \\
\hline
\end{tabular}

${ }^{\mathrm{a}}$ From the inspection and maintenance records of the Viaduct $([50,51])$.

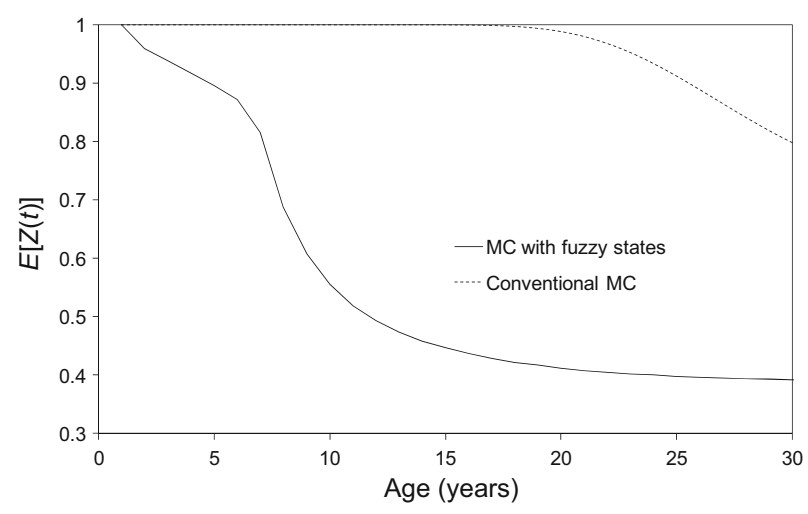

Figure 7. Variation of expected instantaneous reward rate (quality of service) with time.

from figure 7, that the expected quality of service when MC model with fuzzy states is used is lower than that obtained using conventional MC model, suggesting that the use of fuzzy condition states brings in conservatism, which is a desired attribute in engineered decision making. The values of $E\left[W\left(T_{k}\right)\right]$ and $E\left[Y\left(T_{k}\right)\right]$ for different times are also computed using Eq. (10) and are shown in figures 8 and 9, respectively. The times to reach the threshold values of $E\left[Z\left(T_{k}\right)\right]$ for maintenance management decisions are given in table 10. From table 10, it is noted that the time for inspection and repair predicted using the proposed approach are in agreement with the time for observed damage and repair of the actual bridge girder.

The results obtained indicate that for both the reward structures considered, the times to reach the threshold values of $E\left[Z\left(T_{k}\right)\right]$ for maintenance management decisions using the proposed method (MC model with fuzzy states) corroborates the actual engineering decisions taken in the field. However, the membership functions used for the fuzzy states (viz., GOOD, AVERAGE and POOR) have to be calibrated using methodologies which need to be evolved. The value of $E\left[Z\left(T_{k}\right)\right]$ is a measure of the expected performance of the girder at time $T_{k}$. While $E\left[Z\left(T_{k}\right)\right]$ is

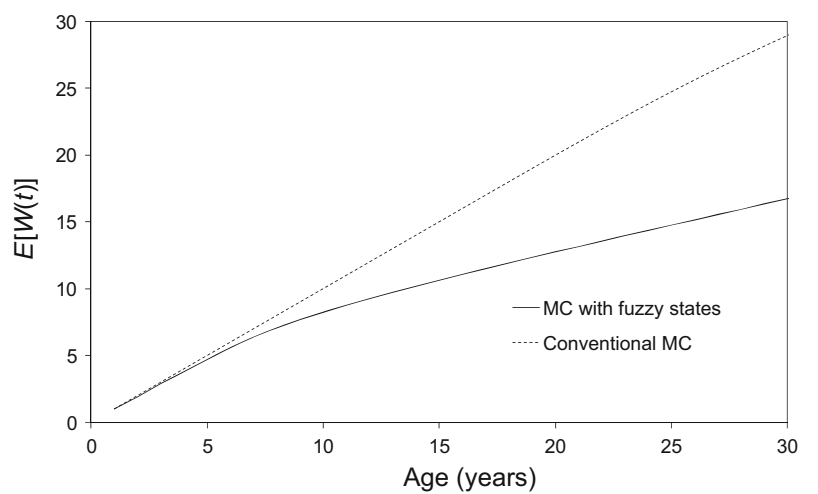

Figure 8. Variation of expected accumulated reward (quality of service) with time.

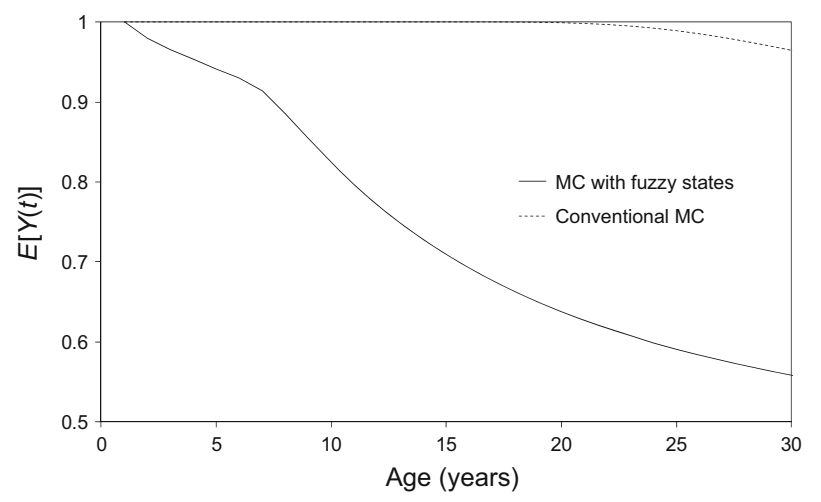

Figure 9. Variation of expected time-averaged accumulated reward (quality of service) with time.

useful for comparing the performance of different bridge girders over time, this measure does not address the likelihood of completing a given amount of work (or satisfying a given level of performance) over time [49]. This aspect is more important for remaining life assessment for the planning of maintenance, and probability distribution of $Z(t)$ will be more useful for this purpose. 
The proposed approach can also be extended for carrying out performability analysis of existing structural members, for which maintenance/rehabilitation is carried out. The probability vector for the condition states can be determined from the expert judgments [36]. This vector can be used along with the NHMC for modeling the condition state evolution, and for performance evaluation.

\section{Summary}

A methodology for performance evaluation of corrosionaffected reinforced concrete bridge girders is proposed. The methodology integrates: (i) non-homogeneous MC model for modeling the stochastic evolution of condition of the bridge girder with time, (ii) fuzzy states to take into account the ambiguities arising due to the linguistic description of states, and (iii) performability measure for describing the performance of the bridge girder. The usefulness of the methodology is illustrated through the performability assessment of a reinforced concrete T-beam bridge girder. From a comparison of the results obtained using MC with fuzzy states to that obtained using conventional MC model, it is noted that the use of MC with fuzzy states leads to conservative decision making.

Scope for future work: The membership functions for the fuzzy condition states can be evolved more rationally by soliciting the responses from the field engineers involved in making decisions repair/retrofit of the distressed bridge girder using well designed questionnaire.

\section{Acknowledgments}

This paper is being published with the kind permission of the Director, CSIR-SERC, Chennai.

\section{References}

[1] Aktan A E, Farhey D N, Brown D L, Dalal V, Helmicki A J, Hunt V and Shelley S J 1996 Condition assessment for bridge management. J. Infrastruct. Syst. ASCE 2(3): 108-117

[2] Durango-Cohen P L and Madanat S M 2008 Optimization of inspection and maintenance decisions for infrastructure facilities under performance model uncertainty: A quasiBayes approach. Transp. Res. A 42: 1074-1085

[3] Godart B and Vassie P R 2001 Bridge management systems: Extended review of existing systems and outline framework for a European system. BRIME Deliverable D13, PL97-2220

[4] Kim S, Frangopol D M and Soliman M 2013 Generalized probabilistic framework for optimum inspection and maintenance planning. J. Struct. Eng. ASCE 139(3): 435-447

[5] Zhu B and Frangopol D M 2013 Risk-based approach for optimum maintenance of bridges under traffic and earthquake loads. J. Struct. Eng. ASCE 139(3): 422-434
[6] Flintsch G W and Chen C 2004 Soft computing applications in infrastructure management. J. Infrastruct. Syst. ASCE 10(4): 157-166

[7] Elhag T and Wang Y 2007 Risk assessment for bridge maintenance projects: neural networks versus regression techniques. J. Comput. Civ. Engg. ASCE 21(6): 402-409

[8] Bolar A, Tesfamariam S and Sadiq R 2013 Condition assessment for bridges: a hierarchical evidential reasoning (HER) framework. Struct. Infrastruct. Engg. 9(7): 1-19

[9] Cheng M and Hoang N 2014 Risk score inference for bridge maintenance project using evolutionary fuzzy least squares support vector machine. J. Comput. Civ. Eng. ASCE 28(3): 04014003(9)

[10] Balaji Rao K, Anoop M B, Lakshmanan N, Gopalakrishnan S and Appa Rao T V S R 2004b Risk-based remaining life assessment of corrosion affected reinforced concrete structural members. J. Struct. Eng. 31(1): 51-64

[11] Cesare M A, Santamarina C, Turkstra C and Vanmarcke E H 1992 Modeling bridge deterioration with Markov chains. $J$. Transp. Eng. ASCE 118(6): 820-833

[12] Chase S B and Gáspár L 2000 Modeling the reduction in load capacity of highway bridges with age. J. Bridge Eng. ASCE 5(4): 331-336

[13] Brown C B and Yao J T P 1983 Fuzzy sets and structural engineering. J. Struct. Eng. ASCE 109(5): 1211-1225

[14] Anoop M B, Balaji Rao K and Lakshmanan N 2008 Safety assessment of austenitic steel nuclear power plant pipelines against stress corrosion cracking in the presence of hybrid uncertainties. Int. J. Pressure Vessels Piping 85(4): 238-247

[15] Corotis R B 2009 Risk communication with generalized uncertainty and linguistics. Struct. Saf. 31: 113-117

[16] Shiraishi N and Furuta H 1983 Reliability analysis based on fuzzy probability. J. Eng. Mech. ASCE, 109(6): 1445-1459

[17] Aktan A E, Ellingwood B R and Kehoe B 2007 Performancebased engineering of constructed systems. J. Struct. Engg. ASCE 133(3): 311-323

[18] Ryan T W, Hartle R A, Mann J E and Danovich L J 2006 Bridge inspector's reference manual. Report No. FHWA NHI 03-001, Federal Highway Administration National Highway Institute, Virginia

[19] NYDoT 1997 Bridge inspection manual, New York State Department of Transportation

[20] Hilsdorf H and Kropp J 1995 Performance criteria for concrete durability. E \& FN Spon, London

[21] Crank J 1975 Mathematics of diffusion. Oxford University Press

[22] Lindvall A 1999 Environmental actions and response survey, inspection and measurement. Working Report, The European Community Brite EuRam Project BE95-1347, Task 7 report

[23] Lindvall A 2001 Environmental actions and response: reinforced concrete structures exposed in wind and marine environments. Thesis for Degree of Licentiate of Engineering, Department of Building Materials, Chalmers University of Technology, Goteborg

[24] fib 2006 Model code for service life design. fib Bulletine 34, International Federation for Structural Concrete, Lausanne

[25] Raupach M, Warkus J and Gulikers J 2006 Damage process due to corrosion of reinforcement bars - Current and future activities. Mater. Corrosion 57(8): 648-653 
[26] Vořechovská D, Chromá M, Podroužek J, Rovnaníková $P$ and Teplý B 2009 Modelling of chloride concentration effect on reinforcement corrosion. Comput. -Aided Civil Infrastruct. Eng. 24(6): 446-458

[27] Rodriguez J, Ortega L M, Casal J and Diez J M 1996 Assessing structural conditions of concrete structures with corroded reinforcement. In: R K Dhir and M R Jones (Eds.) Concrete repair, rehabilitation and protection, E\&FN Spon, London, pp. 65-78

[28] Anoop M B 2009 Remaining life assessment of reinforced concrete structural elements subjected to chloride-induced corrosion of reinforcement. $\mathrm{PhD}$ thesis, Department of Civil Engineering, Indian Institute of Science, Bangalore

[29] Vidal T, Castel A and Francois R 2004 Analyzing crack width to predict corrosion in reinforced concrete. Cement Concrete Res. 34(1): 165-174

[30] Vu K A T and Stewart M G 2005 Predicting the likelihood and extent of reinforced concrete corrosion-induced cracking. J. Struct. Engg. ASCE, 131(11): 1681-1689

[31] Tobias D 2011 Perspectives on AASHTO load and resistance factor design, J. Bridge Eng. ASCE, 16(6), 684-692.

[32] Wang N, O'Malley C, Ellingwood B and Zureick A 2011a Bridge rating using system reliability assessment I: Assessment and verification by load testing. J. Bridge Eng. ASCE 16(6): 854-862

[33] Wang N, Ellingwood B and Zureick A 2011b Bridge rating using system reliability assessment II: improvements to bridge rating practices. J. Bridge Eng. ASCE 16(6): 863-871

[34] AASHTO 2003 Manual for condition evaluation and load and resistance factor rating (LRFR) of highway bridges. American Association of State Highway Officials, Washington, DC

[35] Minervino C, Svakumar B, Moses F, Mertz D and Edberg W 2004 New AASHTO guide manual for load and resistance factor rating of highway bridges. J. Bridge Eng. ASCE 9(1): 43-454

[36] Balaji Rao K, Anoop M B and Lakshmanan N 2004a Modelling the evolutionary non-Guassian processes using NHGMC, Proceedings of the International Congress on Computational Mechanics and Simulation (ICCMS-2004), Indian Institute of Technology, Kanpur, India, 9-12 December 2004, Vol. I. pp 182-189

[37] Frangopol D M, Kallen M-J and van Noortwijk J M 2004 Probabilistic models for life-cycle performance of deteriorating structures: review and future directions. Progr. Struct. Eng. Mater. 6(4): 197-212

[38] Jiang M, Corotis R B and Ellis J H 2000 Optimal life-cycle costing with partial observability. J. Infrastruct. Syst. ASCE 6(2): $56-66$
[39] Lay S and Schie $\beta 1$ P 2003 LIFECON deliverable 3.2: service life models. cbm-Technische Universität München

[40] Bocchini P, Saydam D and Frangopol D M 2013 Efficient, accurate, and simple Markov chain model for the life-cycle analysis of bridge groups. Struct. Saf. 40: 51-64

[41] Prakash Desayi and Balaji Rao K 1989 Markov chain model for cracking of RC beams. J. Struct. Eng. ASCE 115(9): 2129-2144

[42] Ng S-K and Moses F 1996 Prediction of bridge service life using time-dependent reliability analysis. In: J E Harding, G A R Parke and M J Ryall (Eds.) Bridge management 3: Inspection, maintenance, assessment and repair', Proceedings of Third International Conference on Bridge Management, University of Surrey, Guildford, UK, 14-17 April 1996, Taylor \& Francis

[43] Bhattacharyya M 1998 Fuzzy Markovian decision process. Fuzzy Sets Syst. 99: 273-282

[44] Symeonaki M A and Stamou G B 2004 Theory of Markov systems with fuzzy states. Fuzzy Sets Syst. 143(3): 427-445

[45] Sanders W H and Meyer J F 1991 A unified approach for specifying measures of performance, dependability ad performability. In: A Avizicuis and J Lapric (Eds.) Dependable computing for critical applications. Springer-Verlag, pp 515-237

[46] Bolch G, Greiner S, de Meer H and Trivedi K S 1998 Queuing networks and Markov chains: modeling and performance evaluation with computer science applications. John Wiley \& Sons Inc., New York

[47] Platis A 2006 A generalized formulation for the performability indicator. Comput. Math. Appl. 51: 239-246

[48] Platis A, Limnios N and Du M L 1998 Dependability analysis of systems modeled by non-homogeneous Markov chains. Reliab. Eng. Syst. Saf. 61: 235-249

[49] Smith R M, Trivedi K S and Ramesh A V 1988 Performability analysis: Measures, an algorithm and a case study. IEEE Trans. Comput. 37(4): 406-417

[50] Covino B S, Cramer S D, Holcomb G R, Bullard S J and Laylor H M 1999 Postmortem of a failed bridge. Concrete Int. 21(2): 39-45

[51] Cramer S D, Covino B S, Holcomb G R, Bullard S J, Russel J H, Dahlin C M, Summers C A, Laylor H M and Soltesz S M 2000 Evaluation of Rocky Point Viaduct concrete beam, Report No. FHWA-OR-RD-00-18, Oregon Department of Transportation, Oregon

[52] Anoop M B, Balaji Rao K and Appa Rao T V S R 2003 A methodology for durability-based service life design of reinforced concrete flexural members. Mag. Concrete Res. 55(3): 289-303 